\title{
Tip 2 Diabetik Makula Ödemli Hastalarda Tedavi Karşılaştırması
}

\section{Comparison of Treatment in Patients with Type 2 Diabetic Macular Edema}

\author{
${ }^{1}$ Abdülhekim YARBAĞ \\ ${ }^{1}$ Sakarya Üniversitesi Eğitim ve Araştırma Hastanesi, Göz Hastalıkları, Sakarya, Türkiye
}

Abdülhekim Yarbağ: https://orcid.org/0000-0002-4181-1884

\section{ÖZ}

Amaç: Diyabetik makula ödemi (DMÖ) tanılı hastalarda; intravitreal triamsinolon asetonid (IVTA), laser fotokoagülasyon (LFK) ve LFK ile kombine IVTA tedavilerinde etkinlik arasstırması yapmak amaçlanmıștır.

Materyal ve Metot: Hastalar rastlantısal olarak üç ayr gruba ayrıldı: Grup 1, 22 hastanın 30 gözünden oluşmakta olup yaş ortalaması 63,2 y1l idi. Grup 2, 22 hastanın 34 gözünden oluşmakta olup yaş ortalaması 59,9 yıl idi. Grup 3 ise 21 hastanın 27 gözünden oluşmakta olup yaş ortalamas1 64,5 y1 idi. Olgulara tedavi öncesi ve sonrasi 1. 3. 6. ve 9. aylarda en iyi düzeltilmiş görme keskinliği, göziçi basınç (GIB) ölçümü ve fundus muayenesini içeren tam göz muayenesi yapıldı. PERG (Pattern Elektroretinografi) testi ile P50 amplitüdü, HRTII (Heidelberg Retina Tomograph II) testi ile ÖHD (Ödem Harita Değeri) ölçüldü.

Bulgular: Grup 1'de (IVTA+LFK) görme keskinliği 26 $(\% 86,6)$ gözde artarken, $3(\% 10)$ gözde değişmedi, 1 (\% 3,3 ) gözde azaldı. Grup 2'de (LFK) görme keskinliği 18 $(\% 52,9)$ gözde artarken, $10(\% 29,4)$ gözde değişmedi, 6 $(\% 17,6)$ gözde azaldı. Grup 3’te (IVTA) görme keskinliği $20(\% 74)$ gözde artarken, $7(\% 25,9)$ gözde değişmedi, azalma hiçbir olguda gözlenmedi.

Sonuç: IVTA ile birlikte lazer FK kullanımının, tek başına IVTA ve lazer FK kullanımından daha etkili olduğunu gözlemledik.

Anahtar Kelimeler: Diabetik makula ödemi, intravitreal, laser fotokoagülasyon, triamsinolon asetonid

\section{ABSTRACT}

Objective: In the study, it was aimed to compare the effectiveness of intravitreal triamcinolone acetonide (IVTA), laser photocoagulation (LPC), and the LPC combined with IVTA treatments in patients with diabetic macular edema (DME)

Materials and Methods: The patients were randomly separated into three groups: Group 1 (IVTA+LFC) consisted of 30 eyes of 22 patients, and the average age was 63.2 years. Group 2 (LFC)consisted of 34 eyes of 22 patients and the mean age was 59.9 years. Group 3(IVTA) consisted of 27 eyes of 21 patients with a mean age of 64.5 years. The complete eye examination including bestcorrected visual acuity (BCVA), intraocular pressure (IOP) measurements, and the fundus inspection was carried out before and 1.3.6. and 9. months after the treatment. P50 amplitudes were measured with the PERG test, and edema map values (EMV) were measured with HRT II.

Results: In Group 1, the BCVA increased in 26 eyes $(86.6 \%)$, did not change in 3 eyes $(10 \%)$, and decreased in one eye $(3.3 \%)$. In Group 2, the BCVA increased in 18 eyes $(52.9 \%)$, did not change in 10 eyes $(29.4 \%)$, and decreased in 6 eyes $(17.6 \%)$. In Group 3, the BCVA increased in 20 eyes $(74 \%)$ and did not change in 7 eyes $(25.9 \%)$

Conclusions: We observed the use of the laser FC combined with IVTA seems to be more effective than using each other of IVTA and laser FC solely.

Keywords: Diabetic macular edema, intravitreal, laser photocoagulation, triamcinolone acetonide
Sorumlu Yazar / Corresponding Author:

Abdülhekim Yarbağ

Sakarya Üniversitesi Eğitim ve Araștırma Hastanesi,

Göz Hastalıkları, Sakarya, Türkiye

Tel: +05069221102

E-mail: drabdulhekim@gmail.com
Yayın Bilgisi / Article Info:

Gönderi Tarihi/ Received: 07/05/2021

Kabul Tarihi/ Accepted: 30/11/202

Online Yayın Tarihi/ Published: 01/03/2022 


\section{GíRiş}

Diyabetes Mellitus (DM) insülinin biyolojik etkinliğinin veya miktarının azalması sonucu ortaya çıkan bir sistemik hastalıktır. Başlıca komplikasyonları damar endotelini direkt olarak etkilemesi ile böbrek, göz ve kalp üzerindedir. ${ }^{1-3}$ Hastalığın prevelansı hasta yaşı ve hastalık süresi ile ilişkilidir. Tip1 Diyabetes Mellitus'de 20 yılda \%99, Tip2 DM'de 20 yılda \%60 oranında değişik derecelerde retinopati bulunmuştur. ${ }^{4-6}$ Diyabetes mellitusun tedavisinin gelişmesiyle, bu hastaların yaşam süresi uzamış ve hastalığın uzun seyri boyunca gelişen dejeneratif damar değişiklikleri öne çıkmaya başlamıştır. Diyabetik mikroanjiyopati ve nöropati adı altında böbrek, göz, uç kısım dokular gibi birçok doku ve organda başlayan değişiklikler ortaya çıkmakta; hastaların böbrek fonksiyonunun bozulmasına, görme fonksiyonunu kaybetmesine, cilt ve kas organlarının nekrozuna yol açmaktadır. Diyabetik bir kişi diyabet olmayan bir kişiye göre 50-80 kat daha fazla görme fonksiyonunu yitirme riskine sahiptir ve diyabet 30-60 yaş grubunda en yaygın körlük sebebidir. ${ }^{7} \mathrm{Bu}$ hastalarda körlük için önde gelen risk faktörü Diyabetik makula ödemidir (DMÖ). Diyabetik retinopatinin (DR) şiddeti artarken, Diyabetik makulopatinin prevalansı da artmaktadır. Nonproliferatif Diyabetik retinopatili hastaların \%3'ünde makula ödemi izlenirken, orta ve ağır nonproliferatif evrede bu oran \%38, proliferatif retinopati evresinde \%71'e ulaşmaktadır. ${ }^{8-9}$ Makula ödemi, jüvenil başlangıçlı DM ve insüline bağlı DM'de daha yaygın olarak görülmektedir. DMÖ gelişmesinde rolü olduğu anlaşılan biyokimyasal aracıların sayısı gün geçtikçe artmaktadır. Vasküler endotelyal büyüme faktörü (VEGF) endotel, pigment epitelyumu (PE), Müller ve glial hücreler tarafindan yapılmakta ve protein kinaz $\mathrm{C}$ izoformunun uyarılmasıyla damar geçirgenliğini arttırmakta, aynı zamanda retina iskemisine yol açmaktadır. ${ }^{10}$ Diyabetik retinada saptanan biyokimyasal değişiklikler; artmış oksidatif stres, protein kinaz $\mathrm{C}$ aktivasyonu, nonenzimatik glikolizasyon, poliyol yolu ve artmış nitrik oksit olarak özetlenebilir. ${ }^{11}$ İlaveten belirtilirse, oksidatif stres son y1llarda pek çok konu ile ilişkilendirilmiş olup bunlar arasında göz hastalıkları da yer almaktadır. ${ }^{12}$ Değişik araştırmacıların yaptıkları çalışmalarda da grid LFK (Laser fotokoagulasyon) etkinliğinin sınırlı olduğu görülmüş ve laser skarının progresif olarak büyümesi sonucu makulanın olumsuz etkilenebileceği gösterilmiştir. ${ }^{13}$ Yapılan birçok çalışmada IVTA (İntravitreal Triamsinolon Asetonid) prezervan madde içermeyen preperatları tavşanlara uygulanmış ve belirgin bir toksisiteye rastlanmamıştır. ${ }^{14}$ Şüphesiz IVTA enjeksiyonu öncesi yıkama işleminin povidon-iyodinin ile yapılması, bu duruma katkı sağlamıştır. Zira; povidon-iodin, her türlü grişimsel göz müdahelelerinde ve tedavilerinde kullanımı giderek yaygınlaşan önemli bir preperattır. ${ }^{15}$ Triamsinolon asetonidin intravitreal enjeksiyonu ile maksimum bioyararlanımla etki etmesi sağlanmaktadır. Subtenon uygulamaların yetersiz penetrasyon nedeniyle kan-retina bariyerine karşı pek etkili olmadığı gösterilmiştir. ${ }^{16}$

Bu çalışmada Göz Kliniğinde DMÖ tanısı konulan hastalarda IVTA + LFK, LFK, IVTA şeklindeki tedavilerin görme keskinliği, PERG (Pattern Elektroretinografi) (P50) ve HRTII (Heidelberg Retina Tomograph II) üzerindeki etkisini araştırmak amaçlanmıştır.

\section{MATERYAL VE METOT}

Sakarya Üniversitesi Tıp Fakültesi Girişimsel Olmayan Etik Kurulundan izin alınan (Tarih:13.4.2021, karar no: 279) bu çalışma, uluslararası bildirgelerde ön görülen kriterlere göre Erciyes Üniversitesi Tıp Fakültesi Göz Hastalıkları Kliniği'nde 2007 yılında yapılmış Uzmanlık Tezi'nden üretilerek gerçekleştirilmiştir.

Fundus muayenesi ve FFA (Fundus Floresein Anjiyografi) ile DMÖ tanısı konan, 6-13 ay takip edilmiş ve herhangi bir tedavi uygulanmamış 65 olgunun 91 gözü çalışmaya dahil edildi. Görme keskinliği 3 metreden parmak sayımı (mps)'nin altında olan, glokom veya kataraktı olan, tedavi sonrası takibi mümkün olmayacak sistemik hastalığı olanlarla, kontrol altına alınamayan HT ve DM olan olgular çalışma kapsamına alınmadı. Preoperatif dönemde olguların sistemik ve oftalmolojik hikayeleri alındı, detaylı oftalmolojik muayene yapıldı. Snellen eşeli ile en iyi düzeltilmiş görme keskinlikleri (sonrası $\log$ MAR değerine çevrildi), aplanasyon tonometresi ile göz içi basınçları ölçüldü, fundus lensiyle fundus muayenesi yapıldı. FFA, PERG, HRTII ödem haritas1 değeri ile DMÖ tipi ve derecesi belirlendi. Akabinde olgular randomize olarak üç gruba ayrıldı: Grup 1: IVTA ve LFK (IVTA'dan 6 hafta sonra) uygulanan olgular, Grup 2: LFK uygulanan olgular, Grup 3: IVTA uygulanan olgular. Makula laser tedavisinde fokal, grid ve modifiye grid tarzında yeşil argon laser (532 nm dalga boyu) kullanıldı. IVTA enjeksiyonu öncesi her göz povidon-iyodin ile y1kandı, blefarasto yerleştirildi. Tüm hastalara topikal anestezi uyguland1, retrobulber anesteziye ihtiyaç duyulmadi. Topikal anestezi sonrasında insülin enjektörü ile $4 \mathrm{mg} / 0,1 \mathrm{ml}$ triamsinolon asetonid, üst temporal kadrandan limbusa 3-4 mm uzakl1ktan intravitreal olarak ameliyathane koşullarında enjekte edildi. Enjeksiyon uygulanan göz antibiyotikli pomad ile kapatıldı ve komplikasyon açısından değerlendirilmek üzere 1 gün, 1 hafta, 2 hafta aralıklarla kontrole çağrıldı. Olgular tedaviden sonra 1. 3. 6. 9. aylarda kontrole çağrılarak oftalmolojik muayeneleri yapıldı. FFA ile MÖ tipi ve derecesi aynı kişi tara- 
fından değerlendirildi. Tüm kontrollerde DGK (Düzeltilmiş Görme Keskinliği), GİB (Göz İçi Basınç) değeri, fundus muayenesi, PERG, HRTII, ve FFA yapildi.

Pupil dilate edilmeden, cilt elektrodu olarak gümüş klorür kaplı elektrodlar kullanılarak referans elektrodlar dış kantüsün iki santimetre dışına, topraklama elektrodu iki kaşın orta noktasından $2 \mathrm{~cm}$ yukarıya alına yerleştirildi. Topikal anestezik (\% 0.5 proparakain hidroklorür) her iki göze damlatıldıktan sonra alt fornikse limbustan yaklaşık $5 \mathrm{~mm}$ alta HK-loop elektrodlar yerleştirilerek cilde tespit edildi. Hastanın gözlüklerini takması sağlanarak refraksiyonu düzeltildi. PERG yanıtını kaydetmek için düşük eşik filtresi $30 \mathrm{~Hz}$ olacak şekilde ayarlama yapıldı. Stimulus şekli dama tahtası, kontrastm $\% 99$, stimulus frekansı 1,02, dakikadaki stimulus sayıs1 73,2, kazanç zamanı 204, alınacak stimulus sayıs1 150 olarak belirlendi.

İstatistiksel analiz: Ölçülebilen verilerin normal dağılım uygunluğuna bakıldı. Dağıım $\mathrm{x} \pm S D$ olarak tanımlandı. Gruplar arasındaki farkıılığa One Way Anova testi, zamanlar arasındaki farklılığa ise Tekrarlı Varyans analizi kullanıldı. Normal dağılıma uymayan verilerde gruplar arası Kruskal- Wallis Varyans analizi, zamanlar arasındaki farkılığa ise Friedman testi kullanıldı. $p<0,05$ 'den küçük değerler istatistiksel olarak anlamlı kabul edildi.

\section{BULGULAR}

Araştırmaya dahil edilen olguların demografik bilgileri tablo 1'de gösterilmiştir. Tablo 1'de görüldüğü gibi çalışmaya dahil edilen hastaların 32'i erkek, (\%
49,2), 33'ü kadın $(\% 50,8)$ olup yaş ortalaması 62,5 y1l (49-80 y1l arasında) idi.

Grup 1: IVTA ve LFK IVTA'dan 6 hafta sonra LFK uygulanan olgulardan oluşan grup I'in DGK, PERG P50 amplitüdü ve HRTII ÖHD sonuçları tablo 2'de gösterilmiştir.

Tablo 2'de görüldüğü gibi, tedavi öncesi ile sonrası ortalama görme keskinliği, PERG P50 değeri ve ÖHD'ler arasında istatistiksel olarak anlamlı fark bulundu $(\mathrm{p}<0,05)$. GİB değerleri tedavi öncesine göre 1 . ay ve 3 . ayda istatistiksel olarak yüksek iken 6. ay ve 9. ayda anlamlı fark gözlenmedi $(p>0,05)$. Birinci, 3., 6. ve 9. aylar arasında saptanan ÖHD'leri arasında istatistiksel anlamlı farklılık bulunmamas1na rağmen ( $p>0,05)$ ÖHD'deki maksimum azalma 3. ayda gözlendi. Bu grupta DGK, P50 amplitüdü ve HRTII ÖHD'i açısından tedaviden önceki ve sonraki değerleri arasında istatistiksel olarak anlamlı fark mevcuttu $(p<0,05)$. Enjeksiyon sonrası ortalama GİB değişikliği, başlangıç değerlerine göre artmış olarak saptand1 ve tedavi öncesi ve sonrası 1 . ay ve 3. ay GİB değerleri arasında istatistiksel olarak anlamlı farklılı mevcut idi $(\mathrm{p}<0,05)$.

Grup 2: LFK uygulanan olgulardan oluşmakta olup, laser FK tedavisi öncesi ve sonrasi 1. 3. 6. ve 9. aylardaki DGK, P50 amplitüdü ve HRTII ÖHD ortalamaları tablo 3 'te gösterilmiştir.

Tablo 3'te görüldüğü gibi, tedavi öncesi ile sonras1 1. ay, 3. ay, 6.ay ve 9. ay kontrollerinde saptanan ortalama görme keskinliği, PERG P50 değeri ve

Tablo 1. Araştır maya katılanların demografik özellikleri.

\begin{tabular}{|c|c|c|c|c|}
\hline Erkek & Kadın & Yaş Ort. & Erkek\% & Kadın $\%$ \\
\hline 32 & 33 & 62,5 & 49,2 & 50,8 \\
\hline
\end{tabular}

Tablo 2. Grup 1'in tedavi öncesi ve sonrası değerleri.

\begin{tabular}{|l|c|c|c|c|c|c|}
\hline & TÖ & TS 1.ay & TS 3.ay & TS 6.ay & TS 9.ay & P \\
\hline DGK & $1,30 \pm 0,32$ & $0,94 \pm 0,36$ & $0,70 \pm 0,26$ & $0,72 \pm 0,31$ & $0,78 \pm 0,35$ & $<0,05$ \\
\hline P50 & $1,26 \pm 0,99$ & $1,93 \pm 1,40$ & $2,38 \pm 1,20$ & $2,26 \pm 1,30$ & $2,16 \pm 1,23$ & $<0,05$ \\
\hline HRTII-ÖHD & $2,80 \pm 0,90$ & $1,85 \pm 0,53$ & $1,42 \pm 0,30$ & $1,50 \pm 0,38$ & $1,60 \pm 0,46$ & $<0,05$ \\
\hline GİB (mmHg) & $14,67 \pm 2,85$ & $17,72 \pm 3,97$ & $18,75 \pm 3,22$ & $16,03 \pm 3,56$ & $15,94 \pm 3,11$ & $<0,05$ \\
\hline
\end{tabular}

TÖ: Tedavi Öncesi; TS: Tedavi Sonrası; DGK: Düzeltilmiş Görme Keskinliği; PERG: Pattern Elektroretinografi; HRTII: Heidelberg Retina Tomograph II; ÖHD: Ödem Harita Değeri; GİB: Göz İçi Basınç; P değerleri $<0,05$ ve $>0,05$ şeklinde gösterildi; P $<0,05$ istatistiksel olarak anlamlı kabul edildi.

Tablo 3. Grup 2'in tedavi öncesi ve sonrası değerleri.

\begin{tabular}{|l|c|c|c|c|c|c|}
\hline & TÖ & TS 1.ay & TS 3.ay & TS 6.ay & TS 9.ay & P \\
\hline DGK & $1,20 \pm 0,32$ & $1,05 \pm 0,45$ & $0,98 \pm 0,42$ & $1,06 \pm 0,50$ & $1,10 \pm 0,54$ & $<0,05$ \\
\hline P50 & $1,42 \pm 0,95$ & $1,70 \pm 1,35$ & $1,81 \pm 1,43$ & $1,72 \pm 1,44$ & $1,62 \pm 1,40$ & $<0,05$ \\
\hline HRTII-ÖHD & $2,51 \pm 0,72$ & $1,94 \pm 0,56$ & $1,85 \pm 0,60$ & $1,96 \pm 0,63$ & $2,08 \pm 0,72$ & $<0,05$ \\
\hline GİB (mmHg) & $14,68 \pm 3,42$ & $14,46 \pm 3,73$ & $15,04 \pm 2,82$ & $14,85 \pm 2,90$ & $14,73 \pm 3,05$ & $>0,05$ \\
\hline
\end{tabular}

TÖ: Tedavi Öncesi; TS: Tedavi Sonrası; DGK: Düzeltilmiş Görme Keskinliği; PERG: Pattern Elektroretinografi; HRTII: Heidelberg Retina Tomograph II; ÖHD: Ödem Harita Değeri; GİB: Göz İçi Basınç; P değerleri $<0,05$ ve $>0,05$ şeklinde gösterildi; P<0,05 istatistiksel olarak anlamlı kabul edildi. 
Tablo 4. Grup 3'ün tedavi öncesi ve sonrası değerleri.

\begin{tabular}{|l|c|c|c|c|c|c|}
\hline & TÖ & TS 1.ay & TS 3.ay & TS 6.ay & TS 9.ay & P \\
\hline DGK & $1,23 \pm 0,26$ & $0,89 \pm 0,30$ & $0,77 \pm 0,33$ & $0,82 \pm 0,36$ & $0,87 \pm 0,38$ & $<0,05$ \\
\hline P50 (mV) & $1,35 \pm 0,82$ & $2,05 \pm 1,20$ & $2,31 \pm 1,13$ & $2,10 \pm 1,03$ & $1,89 \pm 1,15$ & $<0,05$ \\
\hline HRTII-ÖHD & $2,62 \pm 0,64$ & $1,74 \pm 0,42$ & $1,58 \pm 0,36$ & $1,70 \pm 0,46$ & $1,94 \pm 0,51$ & $<0,05$ \\
\hline GİB (mmHg) & $14,82 \pm 3,15$ & $17,37 \pm 4,51$ & $19,02 \pm 2,95$ & $16,68 \pm 3,82$ & $17,0 \pm 3,56$ & $>0,05$ \\
\hline
\end{tabular}

TÖ: Tedavi Öncesi, TS: Tedavi Sonrası, DGK: Düzeltilmiş Görme Keskinliği, PERG: Pattern Elektroretinografi,, HRTII: Heidelberg Retina Tomograph II, ÖHD: Ödem Harita Değeri, GİB: Göz İçi Basınç. P değerleri $<0,05$ ve $>0,05$ șeklinde gösterildi. P $<0,05$ istatistiksel olarak anlamlı kabul edildi.

ÖHD'leri arasında anlamlı fark mevcut iken $(p<0,05)$, GİB değerleri tedavi öncesine göre 1. ay, 3. ay, 6. ay ve 9. ayda anlamlı fark göstermedi ( $\mathrm{p}>0,05)$. Grup 2'de DGK, P50 amplitüdü ve HRTII ÖHD'i açısından tedaviden önceki ve sonraki değerleri arasında istatistiksel olarak anlamlı fark mevcuttu $(\mathrm{p}<0.05)$. PERG ile saptanan P50 değerlerinde, tedavi öncesi değere göre anlamlı artış tespit edildi. Takip muayeneleri esnasında GİB değerleri, hiçbir gözde 21 mmHg'ın üzerine çıkmamış olup LFK tedavisi sonrası ortalama GİB değişikliği, başlangıç değerlerine göre istatistiksel olarak anlamlı farklılık göstermedi ( $\mathrm{p}>0,05)$.

Grup 3'ün tedavi öncesi ve sonrası 1., 3., 6. ve 9. aylardaki DGK, PERG P50 amplitüdü ve HRTII ÖHD bulguları, tablo 4'te gösterilmiştir.

Tablo 4'te görüldüğü gibi, tedavi öncesi ile sonrası ortalama görme keskinliği, PERG P50 değeri ve ÖHD'leri arasında, istatistiksel olarak anlamlı fark bulundu $(\mathrm{p}<0,05)$. Tedavi sonrası ortalama ÖHD'leri, başlangıç değerlerine göre azalmış olarak saptand1. Bu grupta DGK, P50 amplitüdü ve HRTII ÖHD’i açısından tedaviden önceki ve sonraki değerleri arasinda istatistiksel olarak anlamlı fark mevcuttu $(\mathrm{p}<0.05)$. PERG ile saptanan P50 değerleri tedavi öncesi değer ile karşılaştırıldığında anlamlı artış tespit edildi $(p<0,05)$. GİB değişikliği, başlangıç değerlerine göre istatistiksel olarak anlamlı farklılık göstermedi ( $\mathrm{p}>0,05)$.

\section{TARTIŞMA VE SONUÇ}

Yapılan ilk çalışmalarda makula laser FK tedavisinin makula ödemini etkili olarak azalttığı tespit edilmiştir. ${ }^{17}$ Tedavi edilmeyen gözlerin hiçbirinde ödem azalma göstermezken tedavinin etkili olarak görme kaybını önlediği, görme keskinliğini koruduğu hatta artmaya yol açabildiği görülmüştür. Tedavi edilen hastaların 2. yıl sonunda \% 45'i görme keskinliğinde artma, \% 45'i görme keskinliğini koruma, \% 4'ü ise azalma gösterirken, bu tedaviyi görmemiş grupta sirasiyla artma \% 8, durumunu koruma \% 49 ve azalma \% 43 olmuştur (112). ${ }^{17}$ Bizim çalışmamızda sadece laser FK uygulanan grupta tedaviden sonra 9. ayda 18 (\%52.9) olguda DGK'de artma, 10(\%29.4) olguda durumunu koruma, 6(\%17.6) olguda azalma görüldü.

Diabetik makula ödemi (DMÖ) diyabetes mellitusun en ağır komplikasyonlarından biri olup diabetik hastalarda önde gelen körlük nedenidir. ${ }^{18-19}$ DMÖ hiperglisemi etkisiyle vasküler endotelin bozulması, mikroanevrizma oluşumu, kan-retina bariyerinin bozulması ve vasküler geçirgenliğin artması sebebiyle, damardaki sıvının intraretinal ve subretinal boşluğa birikmesi sonucunda oluşur. DMÖ tedavisinde klasik yöntem makular laser fotokoagulasyon olup, fokal, grid ve modifiye grid olarak yapılmaktadır. Yapılan çalışmalar, laser fotokoagulasyon tedavisinin görmeyi koruma ve ödemi tedavi etmede etkili olduğunu göstermiştir. ${ }^{20-23}$ Fotokoagülasyonun hastalıklı retina pigment epitelini ortadan kaldırıp yerini daha genç ve işlevsel hücrelerin almasını sağlayarak etki ettiğini ileri süren araştırmacılar da vardır. ${ }^{24}$ Ayrıca grid laser fotokoagülasyonun yüksek oksijen tüketicisi fotoreseptörleri tahrip ettiği için iç retina tabakalarındaki oksijen miktarını arttırdığı ve böylece buraya olan kan akımını azalttığı da ileri sürülen bir başka etki mekanizmasıdır. ${ }^{24}$

Literatürde IVTA sonrası arka subkapsüler katarakt oranı \%6-10 arasında bildirilmektedir. ${ }^{25}$ Bizim çalışmamızda grup1'de $5(\% 16,6)$, grup2'de $3(\% 8,8)$, grup3'te 9 gözde $(\% 33,3)$ katarakt görüldü. Son zamanlarda yazarlar dirençli DMÖ tedavisinde IVTA ve laser FK'nin görmeyi artırma ve koruma özeliklerini göz önünde bulundurarak, İVTA ile kombine LFK uygulamayı önermektedirler. Araştırmacılar yaptıkları bir çalışmada, diffüz DMÖ’de İTA'ya ilave olarak LFK uygulamasının görmeyi artırdığını ve makula ödeminin tekrarlamasını azalttığını göstermişlerdir. $^{26}$

Bizim çalışmamızda DMÖ hastalarına uygulanan, IVTA ile kombine LFK, LFK ve IVTA tedavi yöntemlerini tüm grupların tedavi öncesi ve sonrası görme keskinlikleri göz önüne alınarak karşılaştırılınca, IVTA ile kombine LFK grubu, en yüksek ve stabil görme keskinliği göstermekteydi. Yalnızca LFK uygulanan grupta görme keskinliğinde artış daha düşük olarak saptandı. Sadece IVTA uygulanan grupta 1 . ve 3 . aylarda anlamlı şekilde artma mevcut ise de 6. ve 9. aylarda azalma olduğu görüldü.

Yine çalışmamızda IVTA ile kombine LFK tedavisinin düzeltilmiş görmeyi anlamlı şekilde artırdığı ve bu tedavi ile makular ödemin nüks oranının düşük olduğu tespit edilmiştir. Yalnız LFK uygulamasında, düzeltilmiş görme korunmakta ise de görme keskin- 
liğinde artma oranı düşük olarak bulunurken, makula ödeminin uzun süre nüks etmediği görülmüştür. Sadece IVTA uygulamasında ise ilk dönemlerde görme anlamlı oranda artmakta, ancak MÖ nüks oranı yüksek olması nedeniyle tekrarlayan enjeksiyonlara ihtiyaç duyulmaktadır.

Sonuç olarak;

1) DMÖ tedavisinde her üç grupta da başlangıç görme keskinliğine kıyasla başarı elde edilmesine karşın uzun dönem etkinliği göz önüne alındığında laser FK ile kombine IVTA uygulamasının sadece IVTA veya laser FK uygulanan olgulara kıyasla daha etkin olduğu gözlenmektedir.

2) PERG P50 amplitüdü ve HRTII-ÖHD, DMÖ’i olan olgularda uygulanan tedavinin etkinliğini değerlendirmede kullanılabilecek olan testlerdir.

Etik Komite Onayı: Sakarya Üniversitesi Tıp Fakültesi Girişimsel Olmayan Etik Kurulundan alınmıştır (Tarih:13.4.2021, karar no: 279).

Çıkar Çatışması: Yazarlar çıkar çatışması bildirmemişlerdir.

Yazar Katkıları: Fikir - AY; Denetim, Malzemeler, Veri Toplanması ve/veya İşleme - ; Analiz ve/veya Yorum -AY; Yazıyı yazan - AY.

Hakem Değerlendirmesi: Dış bağımsız.

Finansal Destek: Bu çalışma, Erciyes Üniversitesi tarafından tıpta uzmanlık tezi olarak desteklenmiştir.

Teşekkür: Uzmanlık tez danışmanı olan Prof. Dr. Abdullah ÖZKIRIŞ'a katkılarından dolayı teşekkür ederiz.

Diğer Bilgi: Bu çalışma Abdülhekim YARBAĞ'ın "Diabetik makula ödemi olan olgularda intravitreal triamsinolon enjeksiyonu, laser fotokoagülasyon ve intravitreal triamsinolon enjeksiyonu ile kombine laser fotokoagülasyon tedavilerinin karşılaştırılması" adlı uzmanlık tezinden üretilmiştir.

\section{KAYNAKLAR}

1. Ozkiris A, Evereklioglu C, Erkilic K, Tamcelik $\mathrm{N}$, Mirza E. Intravitreal triamcinolone acetonide injection as primary treatment for diabetic macular edema. Eur J Ophthalmol. 2004;14:543-549.

2. Morrison JL, Hodgson LA, Lim LL, Al-Qureshi S. Diabetic retinopathy in pregnancy: a review. Clin Exp Ophthalmol. 2016;44(4):321-334. doi:10.1111/ceo.12760

3. Vijan S. In the clinic. Type 2 diabetes. Ann Intern Med. 2015;162(5):1-16. doi:10.7326/ AITC201503030

4. Yarbağ A, Yazar H, Akdoğan M, Pekgör A, Kaleli S. Refractive errors in patients with newly diagnosed diabetes mellitus. Pak J Med Sci. 2015;31 (6):1481-1484. doi:10.12669/pjms.316.8204

5. Pradeepa R, Mohan V. Prevalence of type 2 diabetes and its complications in India and economic costs to the nation. Eur J Clin Nutr. 2017;71 (7):816-824. doi:10.1038/ejcn.2017.40

6. Klein R, Klein BEK, Moss SE, Davis MDl. The Wisconsin Epidemiologic Study Of Diabetic Retinopathy. II. Prevalence and risk of diabetic retinopathy when age at diagnosis is less than 30 years. Arch Ophthalmology. 1984;102:520-526. doi:10.1001/archopht.1984.01040030398010

7. Kalın HA, Hiller R. Blindness caused by diabetic retinopathy. Am J Ophthalmol. 1974;78:58-67.

8. Bresnick GR. Diabetic macular edema. A review. Ophthalmology. 1986;93:989-997

9. Browning DJ, Stewart MW, Lee C. Diabetic macular edema: Evidence-based management. Indian J Ophthalmol. 2018;66(12):1736-1750. doi:10.4103/ijo.IJO_1240_18

10. Tolentino MJ, Millet JW, Gragoudas ES. Intravenous injections of vascular endothelial growth factor produce retinal ischemia and microangiopathy in an adult primate. Ophthalmology. 1996;103:1820-1828.

11. Ciulla TA, Amodor AG, Zinman B. Diabetic retinopathy and diabetic macular edema. Pathophysiology, screening and novel therapies. Diabetes Care. 2003;26:2653-2664.

12. Yuvaci I, Yazar H. Effects of the topical application of cyclosporin A, propolis and dexamethasone on oxidative stress in rats with corneal neovascularization Online Turkish Journal of Health Sciences. 2020;5(2):271-280. doi:10.26453/ otjhs. 718950

13. Blakenship GW. Diabetic macular edema and argon laser photocoagulation. A prospective randomized study. Ophthalmology. 1979;86:69-75.

14. Schindler RH, Chandler DB, Thresher R. The clearance of intravitreal triamcinolone acetonide. Am J Ophthalmol. 1982;93:415-417.

15. Yazar H, Yarbag A, Balci M, Teker B, Tanyeri P. The effects of povidone iodine $(\mathrm{pH} 4.2)$ on patients with adenoviral conjunctivitisi J Pak Med Assoc. 2016;66(8):968-970.

16. Wilson CA, Berkowitz BA, Sato Y, Ando N, Handa JT. Treatment with intravitreal steroid reduces blood-retinal barrier breakdown due to retinal photocoagulation. Arch Ophthalmology. 1992;110:1155-1159.

17. Olk RJ. Modified grid argon (blue-green) laser photocoagulation for diffuse diabetic macular edema. Ophthalmology. 1986;93:938-50. doi:10.1016/s0161-6420(86)33638-8

18. Klein R, Klein BEK, Moss SE, Davis MD. The Wisconsin Epidemiologic Study Of Diabetic Retinopathy. Diabetic Macular Edema. Ophthalmology. 1984;91:1464-1474.

19. Klein BEK, Horak KL, Maynard JD, Lee KE, Klein R. Association of skin intrinsic fluorescence with retinal microvascular complications of 
long term type 1 diabetes in the Wisconsin Epidemiologic Study of Diabetic Retinopathy. Ophthalmic Epidemiol. 2017;24(4):211-216. doi:10.1080/09286586.2016.1269934

20. Little JL, Zweng HC, Jack RL, Vassiliadis A. Techniques of argon laser photocoagulation of diabetic disk new vessels. Am J Ophthalmol. 1976;82:675-683.

21. Bandello F, Battaglia Parodi M, Lanzetta P, ve ark. Diabetic Macular Edema. Dev Ophthalmol. 2017;58:102-138. doi:10.1159/000455277

22. Romero-Aroca P, Baget-Bernaldiz M, ParejaRios A, Lopez-Galvez M, Navarro-Gil R, Verges R. Diabetic macular edema pathophysiology: vasogenic versus inflammatory. J Diabetes Res. 2016;2016:2156273. doi:10.1155/2016/2156273

23. Kim EJ, Lin WV, Rodriguez SM, Chen A, Loya A, Weng CY. Treatment of diabetic macular edema. Curr Diab Rep. 2019;19(9):68. doi:10.1007/ s11892-019-1188-4

24.Peyman GA, Spitznaz M, Straatsma BR. Peroxidase diffusion in the normal and photocoagulated retina. Invest Ophthalmol Vis Sci. 1971;10:181-189.

25. Özkırış A, Evereklioğlu C, İlhan Ö, Erkılıç K, Mirza E, Doğan H. Diabetik makula ödemi olan olgularda tek doz intravitreal triamsinolonun göz içi basıncına etkisi. Türk Oftalmoloji Gazetesi. 2005;35:426-430.

26. Kang SW, Sa HS, Cho HY, Kim JI. Macular grid photocoagulation after intravitreal triamcinolone acetonide for diffuse diabetic macular edema. Arch Ophthalmol.. Arch Ophthalmol. 2006;93:653-658. 